\title{
Letter
}

\section{Changes in blood parameters in pregnant Japanese White rabbits}

\author{
Ryo Haneda, Yasumoto Mizoguchi, Tetsuya Matsuoka, Hiroyasu Mizuguchi, \\ Takako Endoh, Kazuya Fukuda and Yuzo Asano \\ Kannami Laboratory, Bozo Research Center Inc., Japan, 1308-125, Kuwahara-Sanbonmatsu, Kannami-cho, \\ Tagata-gun, Shizuoka 419-0101, Japan
}

(Received April 19, 2010; Accepted June 15, 2010)

\begin{abstract}
Changes in blood parameters, especially those related to blood coagulations, were examined on gestational days (GDs) 6, 18 and 28 in Japanese White rabbits. As compared with the non-pregnant group, the following changes were observed in the pregnant group. For blood coagulation-related parameters, fibrinogen, platelets and antithrombin time III (ATIII) was significantly increased on GD 18 and/or GD 28, and activated partial thromboplastin time (APTT) was significantly prolonged on GDs 18 and 28. For the other hematological and blood chemical parameters, hemoglobin and hematocrit values were significantly decreased on GDs 18 and 28. Reticulocyte counts significantly and prominently increased on GD 18 and then decreased to significantly lower levels than those in the non-pregnant group on GD 28. Eosinophils and basophil showed significant decreases on GD 18 and/or GD 28. The serum progesterone concentration reached its highest level on GD 18. Total protein (TP), albumin, alkaline phosphatase (ALP), alanine aminotransferase (ALT), cholesterol, calcium, glucose and blood urea nitrogen were significantly decreased on GD 18 and/or GD 28. These results were almost similar to those in the pregnant New Zealand White rabbits (Mizoguchi et al., 2010).
\end{abstract}

Key words: Japanese White pregnant rabbits, Clinical pathology parameters, Blood coagulation

\section{INTRODUCTION}

The pregnant rabbits are frequently and widely used in embryo-fetal development toxicity (teratology) studies. Although the main purpose of the study is to evaluate the embryo-fetal toxicity, it is necessary to consider the secondary effects of maternal toxicity in order to assess precisely the fetotoxicity of the compound administered. However, since there are only a few detailed studies on the changes of hematology and biochemistry parameters in pregnant rabbits (Mariscal et al., 1994; Wells et al., 1999), it is difficult to refer to the secondary effects of maternal toxicity.

We previously examined the changes in maternal blood parameters along the progression of pregnancy in rabbits of the New Zealand White strain (Kbl:NZW) rabbits (Mizoguchi et al., 2010). However, there is a paucity of data pertaining to hematology and blood biochemistry of pregnant Japanese White (JW) rabbits. Therefore, this study was carried out to examine the changes in blood parameters especially those related to blood coagulation in JW rabbits on gestational days (GDs) 6, 18 and 28 in order to compare them with those in pregnant NZW rabbits.

\section{MATERIALS AND METHODS}

Eighteen female rabbits of the Japanese White strain (Kbl:JW, Kitayama Labes, Co., Ltd., Nagano, Japan) at 6 or 7 months of age were used in this study. The animals were maintained individually in aluminum cages in an animal room under controlled conditions (temperature; $22.5 \pm 3.5^{\circ} \mathrm{C}$, relative humidity; $50 \pm 20 \%$, air ventilation; 10 to 15 times per hour, artificial lighting; 12 hr per day), and were allowed free access to diet (RC4, Oriental Yeast Co., Ltd., Tokyo, Japan) and to water via an automatic water supply system (Fuji Water Union, Shizuoka, Japan). After a 1-week acclimation period, 10 females which were judged to be in estrus were housed together with male rabbits from the same colony in cir-

Correspondence: Yuzo Asano (E-mail: asano@bozo.co.jp) 


\section{R. Haneda et al.}

cles $(650 \mathrm{~mm}$ in diameter $\times 500 \mathrm{~mm}$ in height) for mating on a 1:1 basis. The day when copulation was confirmed was regarded as GD 0 . Ten pregnant animals were assigned to the pregnant $(\mathrm{P})$ group and the remaining 8 animals which were not subjected to mating to the nonpregnant (NP) group.

All animals were checked daily for general conditions. Body weights and food consumptions were also recorded during the experimental period.

Blood sampling was done on all animals of the two groups via the auricular artery on GDs 6, 18 and 28 . Hematology (red blood cells [RBC], haemoglobin [Hb], haematocrit [Hct], mean cell volume [MCV], mean cell haemoglobin $[\mathrm{MCH}]$, mean corpuscular haemoglobin concentration [MCHC], reticulocyte, white blood cells [WBC], differential white blood cell count), blood biochemistry parameters (blood urea N [BUN], creatinine, total protein [TP], albumin, alkaline phosphatase [ALP], total cholesterol, triglycerides, glucose, sodium [Na], potassium $[\mathrm{K}]$, calcium [Ca], phosphorus $[\mathrm{P}]$ and chloride $[\mathrm{Cl}]$, aspartate aminotransferase [AST], alanine aminotransferase [ALT], lactate dehydrogenase [LDH] and creatine kinase $[\mathrm{CPK}])$, coagulation-related parameters (fibrinogen, platelets, activated partial thromboplastin time [APTT], prothrombin time [PT] and antithrombin time III [ATIII]) and progesterone concentrations were analyzed according to the methods described in our previous report on (NZW) rabbits (Mizoguchi et al., 2010). All animals were euthanized on GD 28 by exsanguination from the abdominal aorta under pentobarbital anesthesia.

The experimental procedures were conducted according to the Animal Welfare Guidelines of Bozo Research Center Inc.

The means \pm S.D. were calculated for the parameters examined in each group, and were first analyzed for homogeneity of variance by F test between the NP- and P-groups. Then, homogeneous data were analyzed by Student's t-test and heterogeneous data by Aspin-Welch's t-test, respectively. A two-way analysis variance was performed (Group x Day) and there were significant differences for the Group x Day interaction in almost all parameters except for neutrophils, monocytes, LDH, $\mathrm{CPK}$, glucose, Na, K, P, creatinine and platelets so further analysis was performed on the data from each day.

\section{RESULTS}

\section{Body weights and food consumptions}

There were no abnormal clinical signs observed in any animal throughout the gestation period. The body weight was not significantly different between the two groups, although the food consumption in the P-group was 36\% lower than that in the NP-group on GD 28.

\section{Changes in blood coagulation-related parameters}

As to the blood coagulation-related parameters in the P-group, compared with those in the NP-group, fibrinogen, platelet and ATIII values were significantly increased on GD 18 and/or GD 28, and APTT was significantly prolonged on GDs 18 and 28. On the other hand, PT showed no significant changes (Table 1).

\section{Serum progesterone concentration}

The serum progesterone concentration was significantly higher in the P-group than in the NP-group on GDs 6, 18 and 28. The concentration in the P-group peaked on GD 18 (Table 2).

\section{Hematological findings}

As to RBC parameters, RBC, $\mathrm{Hb}$ and Hct were significantly lower in the P-group than in the NP-group on GDs 18 and 28. On the other hand, reticulocytes were significantly higher on GD 18 and significantly lower on GD 28 in the P-group than in the NP-group. There were no significant differences in $\mathrm{MCV}, \mathrm{MCH}$ and $\mathrm{MCHC}$ values between the two groups (Table 3-1).

As to WBC parameters, eosinophils and basophils showed significantly lower values in the P-group than in the NP-group on GD 18 and/or GD 28. Except for a low value of WBC on GD 28 in the P-group, there were no significant changes in other parameters between the two groups (Table 3-2).

\section{Blood biochemical findings}

On GD 18 and/or GD 28, TP, albumin, ALP, ALT and cholesterol values were significantly lower in the P-group than in the NP-group. In the P-group, TP was significantly higher on GD 6, AST on GD 28 and LDH on GD 18, respectively, as compared with those in the NP-group. On the other hand, in the P-group, as compared with the NPgroup, the value of triglycerides was significantly higher on GD 18 while it was significantly lower on GD 28 (Table 4-1). In addition, glucose, $\mathrm{Na}, \mathrm{Ca}, \mathrm{Cl}$, urea $\mathrm{N}$ and creatinine values in the P-group were significantly lower on GD 18 and/or GD 28. On the other hand, Ca and urea $\mathrm{N}$ values on GD 6 were significantly higher in the P-group than in the NP-group. There were no significant differences in $\mathrm{K}$ and $\mathrm{P}$ values between the two groups (Table 4-2). 
Blood parameters in pregnant JW rabbits

Table 1. Changes in blood coagulation-related parameters in pregnant and non-pregnant rabbits

\begin{tabular}{|c|c|c|c|c|c|c|c|}
\hline & Day & $\mathrm{n}$ & $\begin{array}{l}\text { Fibrinogen } \\
\text { (mg/dl) }\end{array}$ & $\begin{array}{l}\text { Platelets } \\
\left(\mathrm{x} 10^{4} / \mu \mathrm{l}\right)\end{array}$ & $\begin{array}{l}\text { APTT } \\
\text { (s) }\end{array}$ & $\begin{array}{l}\text { PT } \\
\text { (s) }\end{array}$ & $\begin{array}{c}\text { АТШ } \\
(\%)\end{array}$ \\
\hline \multirow{3}{*}{ NP } & 6 & 8 & $258 \pm 25$ & $40.2 \pm 10.7$ & $22.2 \pm 3.0$ & $6.4 \pm 0.1$ & $115 \pm 9$ \\
\hline & 18 & 8 & $263 \pm 30$ & $41.6 \pm 13.8$ & $23.1 \pm 3.0$ & $6.5 \pm 0.2$ & $114 \pm 11$ \\
\hline & 28 & 8 & $229 \pm 27$ & $38.3 \pm 7.0$ & $23.0 \pm 2.9$ & $6.2 \pm 0.1$ & $113 \pm 8$ \\
\hline \multirow{3}{*}{$\mathrm{P}$} & 6 & 10 & $249 \pm 30$ & $47.0 \pm 13.3$ & $23.6 \pm 3.2$ & $6.5 \pm 0.2$ & $106 \pm 10$ \\
\hline & 18 & 10 & $324 \pm 49^{* *}$ & $49.9 \pm 13.3$ & $29.4 \pm 5.0^{* *}$ & $6.6 \pm 0.1$ & $127 \pm 10^{*}$ \\
\hline & 28 & 10 & $295 \pm 56^{\# \#}$ & $55.9 \pm 14.5^{\# \#}$ & $33.5 \pm 5.0^{* *}$ & $6.2 \pm 0.1$ & $146 \pm 12^{* *}$ \\
\hline
\end{tabular}

P, Pregnant rabbits; NP, Non-pregnant rabbits; Day, Gestational day in pregnant rabbit or day after sampling point in non-pregnant rabbit; *: $\mathrm{P}<0.05$, **: $\mathrm{P}<0.01$, significantly different from NP group (Student's t-test); \#\#: $\mathrm{P}<0.01$, significantly different from NP group (Aspin-Welch t-test).

Table 2. Changes in serum progesterone concentrations in pregnant and non-pregnant rabbits

\begin{tabular}{lccc}
\hline & Day & $\mathrm{n}$ & $\begin{array}{c}\text { Concentration } \\
(\mathrm{ng} / \mathrm{ml})\end{array}$ \\
\hline \multirow{3}{*}{$\mathrm{NP}$} & 6 & 5 & $0.1 \pm 0.1$ \\
& 18 & 5 & $0.1 \pm 0.2$ \\
& 28 & 5 & $0.1 \pm 0.1$ \\
\hline & 6 & 5 & $5.9 \pm 0.5^{\# \#}$ \\
& 18 & 5 & $8.8 \pm 1.0^{\# \#}$ \\
\hline
\end{tabular}

P, Pregnant rabbits; NP, Non-pregnant rabbits; Day, Gestational day $(\mathrm{P})$ \#\#: $\mathrm{P}<0.01$, significantly different from NP group (Aspin-Welch t-test).

\section{DISCUSSION}

In the present study, changes in blood parameters, especially those related to blood coagulation, were examined on GDs 6, 18 and 28 in JW rabbits and compared them with those in NZW ones (Mizoguchi et al., 2010).

As a result, significant increases in fibrinogen, platelet and ATIII values and significant prolongation of APTT were detected on GD 18 and/or GD 28 as previously reported in NZW rabbits (Mizoguchi et al., 2010). An increase in fibrinogens on GD 28 was more prominent in JW rabbits than in NZW rabbits (Mizoguchi et al., 2010). PT values showed no significant changes like in the case of NZW rabbits (Mizoguchi et al., 2010).

In JW rabbits, main RBC and WBC parameters signif- icantly decreased on GDs 18 and 28, and this was considered to be secondary to hemodilution as reported in pregnant women (Burtis and Ashwood, 1994; DeRijk et al., 2002) and pregnant NZW rabbits (Wells et al., 1999; Mizoguchi et al., 2010).

Reticulocytes drastically increased on GD18 when the serum progesterone concentration reached its peak level, suggesting that the increase of serum progesterone concentration might initiate the enhancement of erythropoiesis (Beischer and MacKay, 1978; DeRijk et al., 2002). There are, however, conflicting reports of reticulocyte changes in pregnant women (Howells et al., 1986; Mercelina-Roumans et al., 1995). TP and albumin in pregnant JW rabbits decreased to the same level as previously reported in pregnant NZW rabbits (Wells et al., 1999; Mizoguchi et al., 2010) and women (Lind, 1980), and this is thought to reflect the increased blood volume. In addition, glucose and cholesterol values decreased on GD 18 and/or GD 28 as previously reported (Wells et al., 1999; Mizoguchi et al., 2010). Well et al. (1999) suggested that the decrease in serum concentration of glucose with the progression of pregnancy might be due to the increased demand for fetal growth. Triglycerides significantly increased on GD 18 and then decreased on GD 28 in JW rabbits as reported in NZW rabbits (Mizoguchi et al., 2009). This suggests that the decreases of cholesterol, ALP and triglycerides values on GD 28 may reflect the decreased food consumption (36\% lower compared with the NP-group).

Serum $\mathrm{Ca}$ and urea $\mathrm{N}$ significantly decreased on GD 18 and/or GD 28. In this connection, it was reported that women exhibited steady decreases in electrolytes because of the demand by the fetus during the fetal growth stage 
R. Haneda et al.

Table 3-1. Changes in red blood parameters in pregnant and non-pregnant rabbits

\begin{tabular}{|c|c|c|c|c|c|c|c|c|c|}
\hline & Day & $\mathrm{n}$ & $\begin{array}{c}\mathrm{RBC} \\
\left(\mathrm{x} 10^{4} / \mathrm{l}\right)\end{array}$ & $\begin{array}{l}\mathrm{Hb} \\
\text { (g/dl) }\end{array}$ & $\begin{array}{l}\text { Hct } \\
(\%)\end{array}$ & $\begin{array}{l}\text { MCV } \\
\text { (fl) }\end{array}$ & $\begin{array}{l}\mathrm{MCH} \\
(\mathrm{pg})\end{array}$ & $\begin{array}{c}\text { MCHC } \\
(\%)\end{array}$ & $\begin{array}{c}\text { Reticulocytes } \\
\left(10 \mathrm{E}^{4} / \mu \mathrm{l}\right)\end{array}$ \\
\hline \multirow{3}{*}{ NP } & 6 & 8 & $674 \pm 33$ & $14.9 \pm 0.6$ & $43.2 \pm 1.7$ & $64.2 \pm 2.2$ & $22.1 \pm 1.0$ & $34.5 \pm 0.8$ & $3.0 \pm 0.4$ \\
\hline & 18 & 8 & $650 \pm 37$ & $14.0 \pm 0.3$ & $40.2 \pm 1.4$ & $62.0 \pm 1.8$ & $21.7 \pm 1.1$ & $34.9 \pm 1.0$ & $3.7 \pm 0.7$ \\
\hline & 28 & 8 & $645 \pm 36$ & $13.9 \pm 0.5$ & $39.9 \pm 1.5$ & $61.9 \pm 2.3$ & $21.6 \pm 1.1$ & $34.9 \pm 0.9$ & $3.6 \pm 0.4$ \\
\hline \multirow{3}{*}{$\mathrm{P}$} & 6 & 10 & $656 \pm 24$ & $14.6 \pm 0.4$ & $43.3 \pm 1.6$ & $66.0 \pm 1.8$ & $22.3 \pm 0.6$ & $33.8 \pm 0.8$ & $2.7 \pm 0.5$ \\
\hline & 18 & 10 & $607 \pm 17 \#$ & $13.4 \pm 0.5^{* *}$ & $37.7 \pm 1.5^{* *}$ & $62.1 \pm 2.2$ & $22.1 \pm 0.6$ & $35.6 \pm 0.6$ & $6.0 \pm 1.1^{* *}$ \\
\hline & 28 & 10 & $560 \pm 25^{* *}$ & $12.0 \pm 0.7^{* *}$ & $34.5 \pm 1.8^{* *}$ & $61.7 \pm 2.7$ & $21.4 \pm 0.8$ & $34.7 \pm 1.0$ & $1.5 \pm 0.4^{* *}$ \\
\hline
\end{tabular}

P, Pregnant rabbits; NP, Non-pregnant rabbits; Day, Gestational day in pregnant rabbit or day after sampling point in non-pregnant rabbit; **: $\mathrm{P}<0.01$, significantly different from NP group (Student's t-test); \#: $\mathrm{P}<0.05$, significantly different from NP group (AspinWelch t-test).

Table 3-2. Changes in white blood cell parameters in pregnant and non-pregnant rabbits

\begin{tabular}{|c|c|c|c|c|c|c|c|c|}
\hline & Day & $\mathrm{n}$ & $\begin{array}{c}\text { WBC } \\
\left(\mathrm{x} 10^{2} / \mu \mathrm{l}\right)\end{array}$ & $\begin{array}{l}\text { Neutrophils } \\
\left(\mathrm{x} 10^{2} / \mu \mathrm{l}\right)\end{array}$ & $\begin{array}{l}\text { Lymphocytes } \\
\left(\mathrm{x} 10^{2} / \mu \mathrm{l}\right)\end{array}$ & $\begin{array}{l}\text { Eosinophils } \\
\left(\mathrm{x} 10^{2} / \mu \mathrm{l}\right)\end{array}$ & $\begin{array}{l}\text { Basophils } \\
\left(\mathrm{x} 10^{2} / \mu \mathrm{l}\right)\end{array}$ & $\begin{array}{c}\text { Monocytes } \\
\left(\mathrm{x} 10^{2} / \mu \mathrm{l}\right)\end{array}$ \\
\hline & 6 & 8 & $68.6 \pm 13.6$ & $14.4 \pm 4.6$ & $45.2 \pm 12.6$ & $1.0 \pm 0.3$ & $3.5 \pm 0.7$ & $3.1 \pm 1.4$ \\
\hline \multirow[t]{3}{*}{ NP } & 18 & 8 & $68.0 \pm 9.2$ & $15.5 \pm 4.6$ & $42.5 \pm 10.0$ & $1.2 \pm 0.4$ & $3.6 \pm 0.8$ & $3.0 \pm 1.2$ \\
\hline & 28 & 8 & $63.1 \pm 10.9$ & $14.3 \pm 5.0$ & $39.1 \pm 9.4$ & $1.2 \pm 0.5$ & $3.1 \pm 0.8$ & $3.1 \pm 1.6$ \\
\hline & 6 & 10 & $76.7 \pm 11.4$ & $16.2 \pm 3.8$ & $51.6 \pm 8.9$ & $1.0 \pm 0.2$ & $3.2 \pm 0.5$ & $3.5 \pm 1.3$ \\
\hline \multirow[t]{2}{*}{$\mathrm{P}$} & 18 & 10 & $72.4 \pm 15.1$ & $14.5 \pm 2.3$ & $49.0 \pm 12.5$ & $0.9 \pm 0.3$ & $2.6 \pm 0.6^{* *}$ & $3.5 \pm 2.1$ \\
\hline & 28 & 10 & $53.8 \pm 10.5$ & $15.4 \pm 3.7$ & $33.0 \pm 10.1$ & $0.4 \pm 0.2^{\# \#}$ & $1.3 \pm 0.5^{* *}$ & $3.1 \pm 1.3$ \\
\hline
\end{tabular}

P, Pregnant rabbits; NP, Non-pregnant rabbits; Day, Gestational day in pregnant rabbit or day after sampling point in non-pregnant rabbit; **: P < 0.01, significantly different from NP group (Student's t-test); \#\#: P < 0.01, significantly different from NP group (AspinWelch t-test).

Table 4-1. Changes in blood biochemical parameters in pregnant and non-pregnant rabbits

\begin{tabular}{ccccccccccc}
\hline & Day & $\mathrm{n}$ & $\begin{array}{c}\text { TP } \\
(\mathrm{g} / \mathrm{dl})\end{array}$ & $\begin{array}{c}\text { Albumin } \\
(\mathrm{g} / \mathrm{dl})\end{array}$ & $\begin{array}{c}\text { ALP } \\
(\mathrm{IU} / \mathrm{l})\end{array}$ & $\begin{array}{c}\text { AST } \\
(\mathrm{IU} / \mathrm{l})\end{array}$ & $\begin{array}{c}\text { ALT } \\
(\mathrm{IU} / \mathrm{l})\end{array}$ & $\begin{array}{c}\mathrm{LDH} \\
(\mathrm{IU} / \mathrm{l})\end{array}$ & $\begin{array}{c}\text { CPK } \\
(\mathrm{IU} / \mathrm{l})\end{array}$ & $\begin{array}{c}\text { Cholesterol Triglycerides } \\
(\mathrm{mg} / \mathrm{dl})\end{array}$ \\
$(\mathrm{mg} / \mathrm{dl})$
\end{tabular}

P, Pregnant rabbits; NP, Non-pregnant rabbits Day, Gestational day in pregnant rabbit or day after sampling point in non-pregnant rabbit; *: $\mathrm{P}<0.05, * *: \mathrm{P}<0.01$, significantly different from NP group (Student's t-test); $: \mathrm{P}<0.05$, \#\#: $\mathrm{P}<0.01$, significantly different from NP group (Aspin-Welch t-test). 
Blood parameters in pregnant JW rabbits

Table 4-2. Changes in blood biochemistry parameters in pregnant and non-pregnant rabbits

\begin{tabular}{|c|c|c|c|c|c|c|c|c|c|c|}
\hline & Day & $\mathrm{n}$ & $\begin{array}{l}\text { Glucose } \\
\text { (mg/dl) }\end{array}$ & $\begin{array}{c}\mathrm{Na} \\
(\mathrm{mmol} / \mathrm{l})\end{array}$ & $\begin{array}{c}\mathrm{K} \\
(\mathrm{mmol} / \mathrm{l})\end{array}$ & $\begin{array}{c}\mathrm{Ca} \\
\text { (mg/dl) }\end{array}$ & $\begin{array}{c}\mathrm{P} \\
(\mathrm{mg} / \mathrm{dl})\end{array}$ & $\begin{array}{c}\mathrm{Cl} \\
(\mathrm{mmol} / \mathrm{l})\end{array}$ & $\begin{array}{l}\text { Urea N } \\
(\mathrm{mg} / \mathrm{dl})\end{array}$ & $\begin{array}{l}\text { Creatinine } \\
\text { (mg/dl) }\end{array}$ \\
\hline \multirow{3}{*}{ NP } & 6 & 8 & $131 \pm 14$ & $147 \pm 2$ & $4.1 \pm 0.3$ & $14.5 \pm 0.3$ & $3.9 \pm 0.7$ & $107 \pm 3$ & & $0.98 \pm 0.23$ \\
\hline & 18 & 8 & $132 \pm 18$ & $146 \pm 2$ & $4.3 \pm 0.5$ & $14.2 \pm 0.3$ & $4.0 \pm 0.5$ & $110 \pm 3$ & $26 \pm 2$ & $0.94 \pm 0.17$ \\
\hline & 28 & 8 & $127 \pm 10$ & $145 \pm 2$ & $4.0 \pm 0.5$ & $14.0 \pm 0.5$ & $3.8 \pm 0.4$ & $108 \pm 3$ & $26=$ & $0.93 \pm 0.14$ \\
\hline \multirow{3}{*}{$\mathrm{P}$} & 6 & 10 & $142 \pm 35$ & $147 \pm 2$ & $4.1 \pm 0.4$ & $15.0 \pm 0.5^{*}$ & $4.0 \pm 0.4$ & $107 \pm 2$ & $27 \pm 3^{*}$ & $0.89 \pm 0.10$ \\
\hline & 18 & 10 & $127 \pm 19$ & $144 \pm 2^{*}$ & $4.0 \pm 0.7$ & $14.3 \pm 0.8$ & $4.1 \pm 0.6$ & $105 \pm 2^{\# \#}$ & $21 \pm 4^{\# \#}$ & $0.78 \pm 0.11^{*}$ \\
\hline & 28 & 10 & $114 \pm 11^{*}$ & $144 \pm 2$ & $3.9 \pm 0.5$ & $12.8 \pm 0.7^{* *}$ & $3.5 \pm 0.5$ & $106 \pm 3$ & $19 \pm 4^{* *}$ & $0.87 \pm 0.13$ \\
\hline
\end{tabular}

P, Pregnant rabbits; NP, Non-pregnant rabbits Day, Gestational day in pregnant rabbit or day after sampling point in non-pregnant rabbit; *: $\mathrm{P}<0.05$, **: $\mathrm{P}<0.01$, significantly different from NP group (Student's t-test); \#: $\mathrm{P}<0.01$, significantly different from NP group (Aspin-Welch t-test).

(Watney and Rudd, 1974).

In the present study, ALP activity, one of the indicators of liver function, significantly decreased on GDs 18 and 28. Wells et al. (1999) reported that a decrease in ALP activity might reflect increased estrogen levels or an increase in the ratio of serum estrogen to progesterone. It has been reported that, in pregnant rabbits, estrogen concentration increased from GD 7 and thereafter it remained relatively stable until the last 2 or 3 days before parturition (Challis et al., 1973; Mariscal et al., 1994), and that progesterone concentration decreased from GD 15 to the last stage of gestation (Challis et al., 1973).

Increased AST activity and decreased ALT activity observed in the present study on GD 28 were consistent with those of NZWs (Mizoguchi et al., 2010). As reported in rats subjected to fasting or restricted feeding (Toropila et al., 2005; Moriyama et al., 2008), the former was considered to be brought about by the hepatic hyperfunction. However, the cause of the latter remains obscure.

In the present study, as mentioned before, serum progesterone concentration reached its highest level on GD 18, and then decreased until GD 28, although plasma estrogen concentration was not examined.

In conclusion, pregnant rabbits of the Kbl:JW strain showed almost the similar changes in blood parameters with those in pregnant rabbits of Kbl:NZW strain, although an increase in fibrinogens was more prominent in JW rabbits than in NZW rabbits.

\section{ACKNOWLEDGMENTS}

The authors would like to thank Dr. Kunio Doi, Professor Emeritus of the University of Tokyo, for critical review of this manuscript.

\section{REFERENCES}

Beischer, N.A. and MacKay, E.V. (1978): Obstetrics and the Newborn. Saunders Ltd., East Sussex.

Burtis, C.A. and Ashwood, E.R. (1994): Clinical chemistry of pregnancy. In Tietz Textbook Clinical Chemistry, 2nd ed, (Burtis, C.A. and Ashwood, E.R., eds.), pp.2107-2148, WB Saunders Company, Philadelphia.

Challis, J.R.G., Davies, I.J. and Ryan, K.J. (1973): The concentrations of progesterone, estrone and estradiol-17 $\beta$ in the plasma of pregnant rabbits. Endocrinology, 93, 971-976.

DeRijk, E.P., van Esch, E. and Flik, G. (2002): Pregnancy dating in the rat: placental morphology and maternal blood parameters. Toxicol. Pathol., 30, 271-282.

Howells, M., Jones, S., Napier, A., Saunders, K. and Cavill, I. (1986): Erythropoiesis in pregnancy. Br. J. Haematol., 64, 595599.

Lind, T. (1980): Clinical chemistry of pregnancy. In Adv Clin Chem, 21, (Latner, A. and Schwarz, M., eds.), pp.1-24, Academic Press, London.

Mariscal, G.G., Sánchez, V.D., Melo, A.I., Beyer, C. and Rosenblatt, J.S. (1994): Maternal behavior in New Zealand white rabbits: quantification of somatic events, motor patterns, and steroid plasma levels. Physiol. Behav., 55, 1081-1089.

Mercelina-Roumans, P., Ubachs, J. and van Wersch, J. (1995): The reticulocyte count and its subfractions in smoking and nonsmoking women. Eur. J. Clin. Chem. Clin. Biochem., 33, 263265.

Mizoguchi, Y., Matsuoka, T., Mizuguchi, H., Endoh, T., Kamata, R., Fukuda, K., Ishikawa, T. and Asano, Y. (2010): Changes in blood parameters in New Zealand White rabbits during pregnancy. Lab. Anim., 44, 33-39.

Moriyama, T., Tsujioka, S., Ohira, T., Nonaka, S., Ikeda, H., Sugiura, H., Tomohiro, M., Samura, K. and Nishikibe, M. (2008): Effects of reduced food intake on toxicity study parameters in rats. J. Toxicol. Sci., 33, 537-547.

Toropila, M., Nováková, J., Daňová, D., Paluchová, K., Kafka, I. 


\section{R. Haneda et al.}

and Laktičová, K. (2005): Changes in the activity of selected adaptive enzymes in laboratory rats in relation to sex during prolonged fasting. Folia Veterinaria, 49, Suppl. 3, 48-50.

Watney, P.J. and Rudd, B.T. (1974): Calcium metabolism in pregnancy and in the newborn. J. Obstet Gynaecol. Br. Commonw.,
81, 210-219.

Wells, M.Y., Decobecq, C.P., Decouvelaere, D.M., Justice, C. and Guttin, P. (1999): Changes in clinical pathology parameters during gestation in the New Zealand white rabbit. Toxicol. Pathol., 27, 370-379. 